\title{
hOW PAST ClIMATE CLUES CAN HELP PREDICT THE FUTURE
}

WE ALL KNOW THE CLIMATE IS CHANGING BUT PREDICTING WHAT THIS MEANS FOR WEATHER SYSTEMS IS NO EASY MATTER. PROFESSOR ZHENGYU LIU AND DR BETTE OTTO-BLIESNER ARE USING STATE-OF-THE-ART COMPUTER MODELS TO DELVE INTO OUR PLANET'S PAST, TO SEE HOW INSIGHTS INTO PREVIOUS CLIMATIC CHANGES CAN HELP INFORM OUR FUTURE

\section{TALK LIKE A CLIMATE SCIENTIST}

CLIMATE CHANGE - a change in

the global climate, leading to changes in

temperatures, weather and other factors

CLIMATE MODEL - a computer

simulation of the world's past, present or possible future climate

MELTWATER - water formed from melting ice sheet

MONSOON - a seasonal influx of rain brought in by prevailing winds

OCEAN CURRENTS - the motion of the ocean, driven by wind, water density differences and tides

PALEODATA - data that give information about ancient times

\section{SOLAR RADIATION - sunlight,}

including the electromagnetic radiation that results in heat
Climate change does not just mean the world is getting hotter; it signals a whole range of effects on planetary systems, affecting everything from weather patterns to ocean currents. Getting to grips with what climate change means for the world - and for humanity - is essential for two reasons. Firstly, it strengthens the case for action to mitigate climate change as soon as possible. Secondly, it helps us prepare for the changes that might be inevitable, helping to build resilience into human society.

We are witnessing our climate change at an unprecedented pace and, so, it is not easy to say what will happen next. Our best way of predicting the future is by using computer models that simulate the Earth's systems and make projections about what lies in store. However, to ensure that these models are accurate and not making misleading predictions, we have to make sure they match up to the real world - in other words, we must compare them to past incidents of climate change. Professor Zhengyu Liu, of Ohio State University, and Dr Bette Otto-Bliesner, of the National Center for Atmospheric Research in Colorado, have joined forces to do just this, building models that simulate what the planet's climate has been through over the last 21,000 years. They call their project Transient Climate Evolution, or TraCE for short.

LOOKING BACK TO LOOK FORWARD

"To predict the future, we need to know the past," says Liu. "Climate models used to project future impacts need to be tested against past climate records." TraCE compares two distinct lines of scientific enquiry, looking for similarities and differences between the two. The first is the computer model: Liu and Bette use the Community Earth System Model (CESM), which incorporates the latest scientific understanding and technological capabilities to build a computer model that is as true to the real world as possible. The second is paleodata: this is prehistorical evidence left behind on the Earth that we can use to infer what past climates would have been like.

Examining how closely the simulation and real-world data match up helps scientists ascertain both the quality of the computer models and the conclusions drawn from the paleodata. If they 'predict' past consequences of climate change that we know did happen, then they are good models. "Studying past climates provides a natural 'laboratory' to fully understand the Earth system beyond what people have measured directly in the last couple of centuries," says Bette. "The Earth's climate has fluctuated a lot in the past - it has gone through periods of much warmer and colder climates, and rapid transitions between the two."

\section{THE COMMUNITY EARTH}

\section{SYSTEM MODEL}

Climate models are becoming ever-more sophisticated and much of this is down to the increasing capabilities of computers. "Enhanced supercomputers have made it possible to run state-of-the-art climate models for ultra-long simulations, which is what TraCE is based on," says Liu. CESM's simulation accounts for atmospheric greenhouse gases, solar radiation entering our atmosphere, the role of ice sheets, ocean currents and meltwater, among many other factors. It also models how these all interact with one another.

CESM can also account for how things have physically changed over the last 21,000 years: the distance between the Earth and the Sun, which affect sunlight reaching the earth; the 


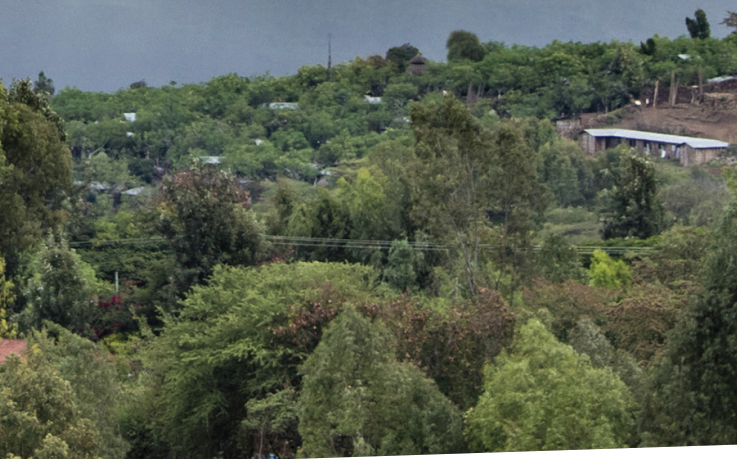

shape of continents and oceans; ice sheets and mountains; and the composition of the atmosphere, including greenhouse gases. The model is regularly supplemented with an evergrowing depth of scientific understanding. "By incorporating our new knowledge of planetary processes and how they interact into the models, we can make them ever-more accurate," says Bette.

\section{CLIMATE CLUES FROM THE PAST}

It is all very well building all these factors into computer models, but there must be a way to check that they are making accurate predictions. This can be done by 'calibrating' the model with data gleaned from the prehistorical record. Scientists are finding increasingly insightful ways of making inferences from the clues left behind on Earth.

Ice cores and sediment cores form the backbone of climate paleodata. A core is a vertical sample of ice or sediment extracted from an area of interest. The core effectively acts as a 'timeline' - the ice or sediment nearer the top of the core will have been laid down recently, whilst that nearer the bottom will have been laid down a long time ago. By studying the characteristics of the ice or sediment at different points on the core that correspond to different points in the past, we can find clues about what the world used to look like. For ice cores, these clues include things like bubbles of greenhouse gases, particles of dust or ash, and oxygen isotopes that act as a proxy for past temperatures. Sediment cores can include pollen, which give an indication of the sort of vegetation that used to grow in an area which, by comparing

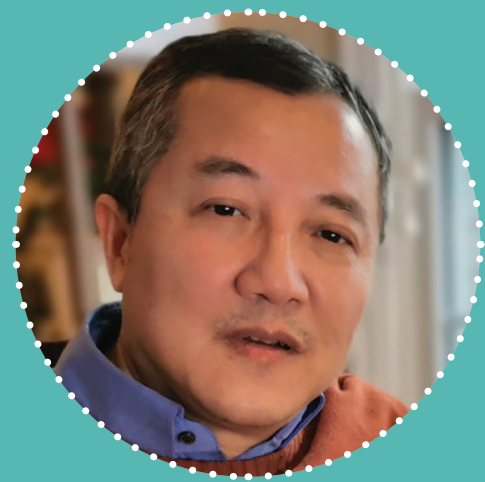

PROFESSOR ZHENGYU LIU

Max Thomas Professor of Climate Dynamics, Department of Geography, Ohio State University, USA.

\section{FIELD OF RESEARCH}

Climate Dynamics

$\ldots \ldots \ldots \ldots$

\section{RESEARCH PROJECT}

Using climate models and historical data to predict the relationship between the Atlantic Meridional Overturning Circulation and abrupt climate change.

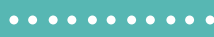

\section{FUNDERS}

US National Science Foundation, US Department of Energy,

Natural Science Foundation of China

to modern-day knowledge about plants' living conditions, can help us infer what that area's climate used to be like.

Neither of these methods give us a perfectly accurate window into the past, but by comparing results with each other and with other sources of paleodata, we can build a good picture. Being able to compare these deductions with computer models such as the CESM means there is even more room for taking a critical look and fine-tuning our knowledge of our planet's history ever further.

\section{THE AFRICA PUZZLE}

Although they collaborate on the TraCE project, Liu and Bette's specialisms lead to them focusing on different areas. Bette's work covers the interaction between climate change and the monsoon season in Africa and Asia. One peculiar finding from delving into the planet's past was a period known as the 'African Humid Period'. This time, from 14,700 to 5,000 years ago, saw an abrupt increase in rainfall in Africa, so much so that deserts turned into grasslands and savannahs.

Scientists found an explanation for why this

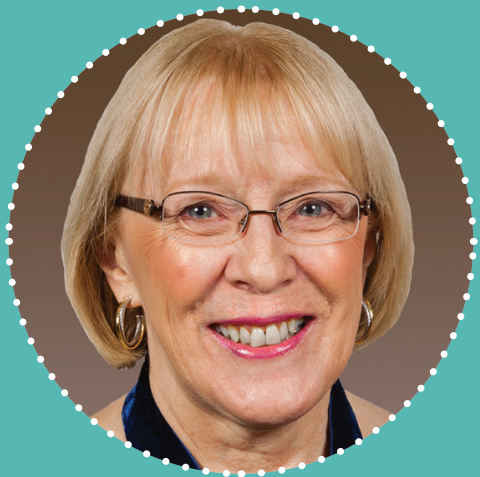

DR BETTE OTTO-BLIESNER

Senior Scientist, National Center for Atmospheric Research (NCAR), Boulder, Colorado, USA.

\section{FIELD OF RESEARCH}

Meteorology and Climatology $\ldots \ldots \ldots \ldots$

\section{RESEARCH PROJECT}

Using climate models and historical data to predict the relationship between regional climate change and monsoon patterns in Africa and Asia.

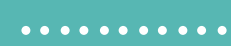

\section{FUNDERS}

US National Science Foundation, US Department of Energy

might have happened for those areas north of the equator: the Earth's orbit had a 'wobble' at the time, due to its gravitational interactions with other celestial bodies such as Jupiter and Saturn. This meant that the northern hemisphere was closer to the Sun in summer, leading to stronger summer temperatures that strengthened monsoon winds and led to more rainfall.

However, large swathes of Africa south of the equator also experienced more rain, which cannot be explained by this wobble, since the southern hemisphere would be further from the Sun during its summer. "Our CESM simulation revealed the role of two other factors," says Bette. "A change in Atlantic Ocean currents, coupled with a rise in greenhouse gases, rapidly boosted rainfall in the region." The role of greenhouse gases in this phenomenon can help us predict more accurately what the effects of climate change may look like this time around, which will have major consequences for Africa's agriculture industry and other sectors.

ATLANTIC CURRENT EVENTS

These findings also link to Liu's specialism, 
which is the interaction between climate change and ocean currents. Ocean currents act like a 'conveyor belt', ensuring that oceanic waters are continuously in circulation. This has big implications for life on Earth: for instance, the Gulf Stream ensures that Europe has relatively mild weather, while the EI Niño current ensures that nutrients that have sunk to the seafloor are periodically brought back into surface waters off the coast of Peru.

A major current system, that feeds into all ocean currents around the world, is the Atlantic Meridional Overturning Circulation (AMOC). There is some evidence that this circulation has weakened in recent years. Historical evidence and climate models suggest that this could lead to a feedback loop meltwater from the polar regions weakens the $A M O C$, which accelerates the rate of climate change. This raises the possibility of a 'tipping point' in the Earth's near future where an abrupt change to the climate takes place.
TRACE IN ACTION

Through these findings and many others, TraCE has led to significant steps forward in our understanding of global climate since the Last Glacial Maximum (LGM). The LGM was about 21,000 years ago, when the planet was around $6^{\circ} \mathrm{C}$ colder, and glaciers were at their furthest extent. For this time period, TraCE has found that the CESM simulation overall matches up well with inferred climate changes from paleodata, particularly in areas such as Greenland, Antarctica, Africa, the tropical Pacific and the Southern and Deep Oceans.

However, findings do not always match up - for instance, Liu and Bette found that historical data showed a weak global cooling trend over the last 10,000 years, whereas the model indicated a weak global warming trend for the same period. Having dug into it further, the researchers believe this is due to shortcomings both in the data and the model. "The inconsistencies are likely partly due to a data bias towards the summer season and inadequate representation of feedback processes in the model," says Liu. Now they know this, they can go back and work on making our understanding of the historical record more accurate and the computer model truer to life.

Key to these processes is collaboration. Although Liu specialises in climate dynamics and Bette in atmospheric sciences, by combining their different strands of knowledge they can accelerate the rate of scientific knowledge. This is enriched by collaboration with many others - entire teams of scientists, computer modellers, engineers, geologists and more, all work together to ensure we have as comprehensive a picture of our planet's past and future as possible.

\section{HOW TO BECOME A CLIMATOLOGIST}

Liu specialises in climate dynamics. This field involves studying the processes behind the global climate system and how they change over time. This includes the interactions of the atmosphere, oceans and ice,

bodies of land and biological organisms.

There are some undergraduate degrees in climatology. A number of other undergraduate degrees, including physics, applied mathematics, Earth sciences, and chemistry, can also lead to a career in climate dynamics.

According to QS World University Rankings, the best universities in the world for physics (as an example) are MIT, Stanford, Harvard, Cambridge, and Oxford.

- According to PayScale, the average climatologist salary in the US is $\$ 70 k$.

\section{PATHWAY FROM SCHOOL T० GLIMATOLOGIST}

Liu recommends taking mathematics at school, as well as the sciences, especially physics and chemistry. Other subjects such as computer science could also be useful.

\section{HOW TO BECOME AN ATMOSPHERIC SCIENTIST}

- Bette specialises in atmospheric science. This involves understanding the processes within the atmosphere and how they link to weather and climate patterns, including interactions with longer climatic changes.

- There are meteorology undergraduate degrees available, but a career in meteorology can also be secured following a degree in physics, atmospheric sciences, maths or computer science.

- According to QS World University Rankings, the best universities in the world for meteorology and atmospheric sciences are the University of Colorado at Boulder, University of Washington, Colorado State University, University of Reading (UK) and California Institute of Technology.

- According to PayScale, the average meteorologist salary in the US is around \$57.6k. Pay scales really depend on degree (B.S., M.S. or Ph.D), employer (academic, government or business) and seniority.

PATHWAY FROM SCHOOL TO ATMOSPHERIC SCIENGE

Bette recommends subjects such as maths, physics, chemistry, statistics and computer programming. 


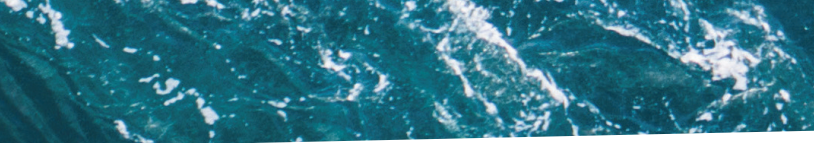

\section{. HOW DID LIU AND BETTE BECOME CLIMATE SCIENTISTS?}

WHAT WERE YOUR INTERESTS AS A CHILD?

$\mathrm{L}$ : When I was younger I was more interested in painting and literature than science. Nature always drew my curiosity, which is perhaps where my scientific interests arose.

B: I loved watching the weather! I was always curious about understanding what led to the weather patterns I could see.

WHAT INSPIRED YOU TO BECOME A SCIENTIST?

L: I don't remember any particular reason, other than my interest in the natural world, which likely drew me to science.

B: Maths and science were my favourite subjects in school and university. In many classes I was one of only a few females, but I always had the support of my teachers and my parents.

WHAT ATTRIBUTES MAKE A

SUCCESSFUL SCIENTIST?

$\mathrm{L}$ : Keeping your curiosity is a key factor.

B: Collaborating with those who have different areas of expertise is essential. The Earth is a complex and interconnected system, after all.

\section{WHAT DO YOU FIND MOST}

REWARDING ABOUTYOUR WORK?

L: I love being able to uncover some of the secrets of the natural world that are hidden within the climate system.

B: Communicating about the importance of understanding past climates to prepare us for the future brings me the most satisfaction.

WHAT ARE YOUR PROUDEST CAREER ACHIEVEMENTS?

$\mathrm{L}$ : Developing TraCE is definitely one of my best accomplishments. I am also proud of some fundamental theories on climate variability that I developed.

B: Of course, TraCE is one of my proudest achievements and has been many decades in the works. I have also served as a lead author on two IPCC (Intergovernmental Panel on Climate Change) reports, which was an honour. This led to me being a corecipient of the Nobel Peace Prize in 2007.

\section{Ty}

\section{LIU AND BETTE'S" TOP TIPS}

01 Keep your curiosity about the world around you - always ask yourself, why does this work the way it does?

02 Always be persistent. The answer to a scientific challenge could be just around the corner.

03 Maths and the sciences are essential components of a lot of research, so it is worth getting a solid grounding in them.
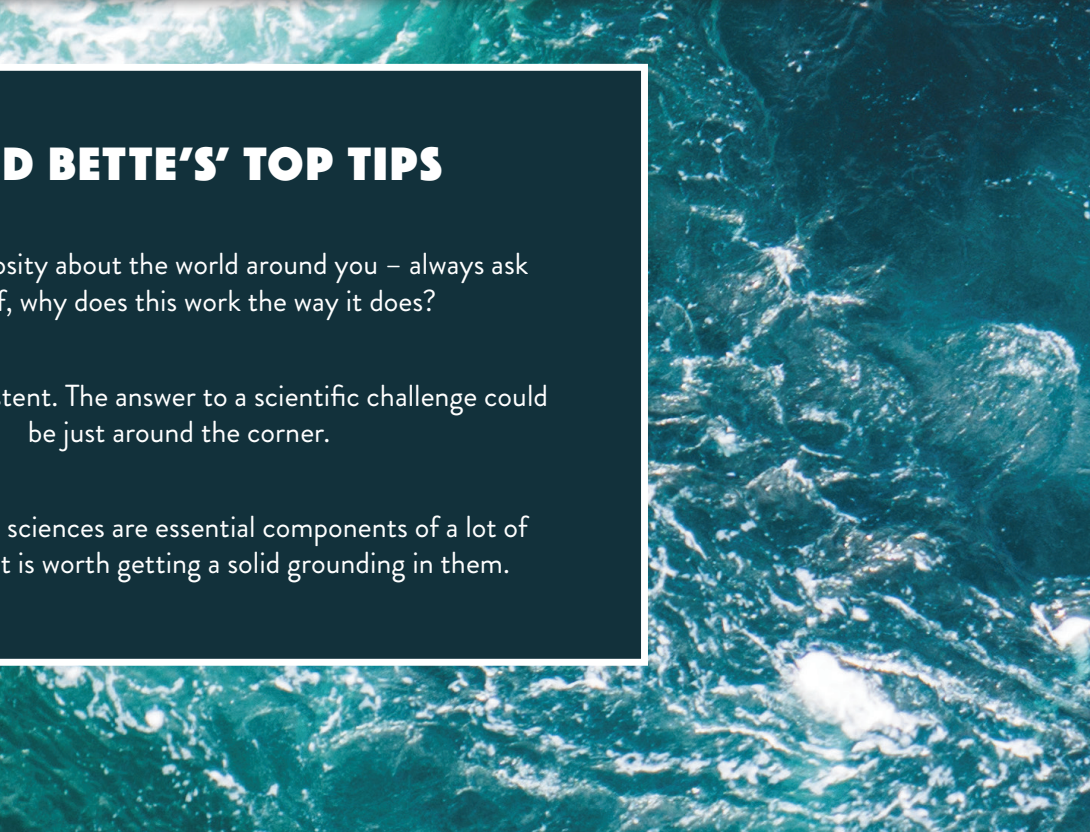